\title{
Mass spectrometry based imaging techniques for spatially resolved analysis of molecules
}

\author{
Andrea Matros and Hans-Peter Mock* \\ Leibniz Institute of Plant Genetics and Crop Plant Research, Gatersleben, Germany
}

Edited by:

Setsuko Komatsu, National Institute of Crop Science, Japan

\section{Reviewed by:}

Sebastien Carpentier, KULeuven, Belgium

Yohei Nanjo, NARO Institute of Crop

Science, Japan

Pietro Franceschi, Research and

Innovation Centre - Fondazione E.

Mach, Italy

\section{*Correspondence}

Hans-Peter Mock, Leibniz Institute of

Plant Genetics and Crop Plant

Research, Corrensstrasse 3, 06466

Gatersleben, Germany.

e-mail: mock@ipk-gatersleben.de
Higher plants are composed of a multitude of tissues with specific functions, reflected by distinct profiles for transcripts, proteins, and metabolites. Comprehensive analysis of metabolites and proteins has advanced tremendously within recent years, and this progress has been driven by the rapid development of sophisticated mass spectrometric techniques. In most of the current "omics"-studies, analysis is performed on whole organ or whole plant extracts, rendering to the loss of spatial information. Mass spectrometry imaging (MSI) techniques have opened a new avenue to obtain information on the spatial distribution of metabolites and of proteins. Pioneered in the field of medicine, the approaches are now applied to study the spatial profiles of molecules in plant systems. A range of different plant organs and tissues have been successfully analyzed by MSI, and patterns of various classes of metabolites from primary and secondary metabolism could be obtained. It can be envisaged that MSI approaches will substantially contribute to build spatially resolved biochemical networks.

Keywords: mass spectrometry, imaging, secondary metabolites, primary metabolism, proteins, peptides, metabolite distribution

\section{BACKGROUND}

Spatially resolved analysis of metabolites and proteins has become feasible within recent years by the development of mass spectrometry imaging (MSI) strategies. Development and application of these techniques has been pioneered in medicinal and pharmacological research. MS imaging allowed the detection of novel clinical markers for better diagnosis of cancer tissues and to follow the spatial-temporal patterns of drug molecules used for pharmacological studies (Rauser et al., 2010; Schwamborn et al., 2010).

The application of MSI strategies has now also been introduced in plant research. As higher plant organs are composed of a multitude of tissues, information on the spatial distribution of proteins and metabolites will be essential to generate improved models of metabolism and to assign biochemical functions of specific tissues. Sample preparation is a major bottleneck for successful MSI of plant tissues. The majority of the MSI studies on plants published to date have addressed the spatial distribution of certain classes of metabolites or of peptides or small proteins. Application of MSI of large proteins still provides considerable difficulties in practice. In the paper current strategies to address these limitations in MSI of plant proteins will be discussed. The particular advantages of MSI set-ups such as matrix-assisted laser desorption ionization (MALDI) MS or desorption electrospray ionization (DESI) MS will be highlighted. Approaches complementary to the MSI strategies will be briefly mentioned, in particular the use of laser microdissection of defined areas of tissue sections. Finally, data evaluation and integration into modeling approaches will be addressed.

\section{MSI SAMPLE PREPARATION}

Any sample preparation technique for MSI analyses aims on keeping the lateral resolution and the nature of the target molecules. According to the applied MSI technique it varies from just mounting a sample for surface analysis to delicate sectioning and matrix application procedures. Some recent publications provide detailed protocols on plant sample preparation for small molecule MSI (Peukert et al., 2012), as well as for protein MSI (Grassl et al., 2011). Strategies for optimized sectioning have been proposed such as varying conditions for sample freezing (e.g., dry ice for water rich samples), section mounting (e.g., embedding in water or gelatin for tiny or flat samples), variation of section thickness (10- to $35-\mu \mathrm{m}$ ), or section drying. Washing steps applied on the sectioned samples will impact on the classes of molecules retained on the tissue surface. Small molecules can be removed to improve imaging of peptides and proteins (Kaspar et al., 2011). Also, the choice of matrix and application strategy strongly influences the sort of molecular species which are ionized and the lateral resolution of the MS images. An increasing number of matrices for various applications have been recently explored and the interested reader is kindly referred to relevant publications (Svatos, 2010; Greer et al., 2011; Kaspar et al., 2011). For reproducible matrix application the most widely used deposition techniques are spraying with a simple airbrush and the use of a dedicated instrument to obtain vibrational vaporization. In our hands vibrational vaporization using a commercial device (ImagePrep, Bruker Daltonics, Germany) is most suitable to adjust optimal spraying and drying times, such as needed for multiple matrix layers and tryptic digestion on tissue sections. 


\section{MSI TECHNIQUES}

All MSI techniques represent surface analysis techniques which are based on desorption and ionization of molecules followed by their subsequent MS data recording (Chaurand, 2012). The most common technique applied for MSI of metabolites and peptides is MALDI MSI, involving the application of a suitable matrix substance on the surface (Caprioli et al., 1997). Other common ionization processes are DESI utilizing a solvent stream (Takáts et al., 2004), secondary ion mass spectrometry (SIMS) making use of an ion beam (Vickerman, 2011), and laser ablation electrospray ionization (LAESI) (Nemes and Vertes, 2012). As DESI and LAESI techniques operate exclusively under atmospheric pressure (AP), sample preparation and associated issues are minimized. Most SIMS and MALDI sources operate in a vacuum chamber, which leads to the loss of volatile compounds and requires careful sample preparation (Chughtai and Heeren, 2010; Kaspar et al., 2011). Cryosectioning is a common procedure to prepare tissue sections for subsequent MALDI MSI (please refer to section MSI Sample Preparation). The spatial resolution currently achieved differs between the various ionization techniques. The highest spatial resolution $(<1 \mu)$ of current instruments is achieved for SIMS. Due to high fragmentation and low ionization efficiency, the size of biological molecules detected by SIMS analysis is limited. Instead, MALDI MSI has been favored with a current limit for spatial resolution of about $10 \mu \mathrm{m}$ (Lee et al., 2012). Spatial resolution in MALDI MSI is influenced by the laser spot size, but is also strongly dependent on matrix application. Formation of large matrix crystals will negatively impact the spatial resolution to be achieved for the sample (Svatos, 2010; Peukert et al., 2012). DESI and LAESI techniques can be applied when the surface chemistry of the sample itself is of interest. Due to the low input for sample preparation, these approaches are suitable of screening larger sample sets (Svatos, 2010).

Various commercial mass analyzers are available for MSI providing sufficient: (i) mass resolution, (ii) spatial resolution, and (iii) MS scan speed. However, selection of one or another technique remains a compromise as none of the available mass analyzers meets perfectly all criteria, e.g., high resolution mass spectrometer typically have slower scan speed (Lee et al., 2012). The recent implementation of tandem mass spectrometry has encouraged MSI applications in plant research by enabling the identification of metabolites and, via on tissue digestion, $\mathrm{N}$-terminal peptide derivatization and CID tandem MS, by facilitating the identification of polypeptides (Horn et al., 2011; Lunsford et al., 2011; Muller et al., 2011).

\section{MSI OF SMALL MOLECULES}

Imaging of small molecules including different classes of primary and secondary metabolites are the most frequent applications to date within plant MSI (Burrell et al., 2007; Kaspar et al., 2011; Lee et al., 2012; Peukert et al., 2012). Studies with a focus on method development and technology application on metabolites that are readily accessible for analysis are still highest abundant among available publications. However, an increasing number of experimental applications became available recently and an overview is presented in Table 1. Differential distribution pattern have been evaluated for a number of molecular species, namely, lipids, amino acids, and sugars, as well as high abundant secondary metabolites, such as polyphenols, anthocyanins, alkaloids, and glucosinolates from a variety of plant species. In the following, we will describe a number of selected examples in more detail.

Most analyses still rely on MALDI MSI techniques with variant matrices applied. For example MALDI MSI was applied to visualize the lipid species in cotton seed tissues (Horn et al., 2012). The comprehensive MSI study demonstrated distinct spatial patterns for molecular species of triacylglycerols and phosphatidylcholine. The MSI data set contained also information on a wide range of other lipid molecules, such as phosphatidylethanolamines, phosphatidic acids, sterols, and gossypol, supporting the wide applicability of the imaging approach (Horn et al., 2012). Also, non-uniform distribution of glucosinolates within Arabidopsis leaves was revealed by MALDI MSI (Shroff et al., 2008). Repeated spraying of the matrix 9-aminoacridine allowed the extraction of glucosinolates from the tissue beneath the surface. The major glucosinolates of the leaves were more abundant in tissues of the midvein and in the periphery when compared to the inner lamina. This pattern seemed to determine the feeding preference of insect larvae for the inner lamina (Shroff et al., 2008).

The application of colloidal graphite (GALDI) enabled the MSI of various small molecules in Arabidopsis surfaces and tissue sections (Cha et al., 2008). When analyzing leaf surfaces, very long chain fatty acids (C26, C28, and C30) were observed. Mass signals diagnostic for flavonoids, which localized within the cells, were only observed at positions were the leaf samples were damaged. When the surface epicuticular waxes were removed by dipping the leaves briefly into chloroform, the signals for fatty acids were strongly reduced. Instead, ions corresponding to kaempferol derivatives became apparent. MSI of flower leaves and stem sections also demonstrated heterogeneous distribution of flavanoids in this organs (Cha et al., 2008).

Matrix free UV-laser desorption/ionization (LDI) MSI at the single cell level provided information on the spatial distribution of UV-absorbing secondary metabolites for Arabidopsis thaliana (kaempferol derivatives) and Hypericum species (phloroglucinols and naphthodianthrones) (Hoelscher et al., 2009). The authors thoroughly confirmed and complemented the MSI data by analysis of isolated glands obtained through microdissection (Hoelscher et al., 2009).

Barley leaf tissue was subjected to MSI using direct and indirect DESI (Li et al., 2011) revealing a homogeneous distribution of hydroxynitrile glucosides. For direct DESI, the epidermis was stripped off and its back was analyzed. Indirect DESI was performed on imprints from intact leaves and of peeled epidermal strips using porous teflon. The indirect approach allowed relative quantification of these compounds in three divergent barley cultivars, namely Mentor, Golden Promise, and Emir (Li et al., 2011).

Only recently approaches have been published that utilize a combination of MALDI MS for imaging and high resolution MS for identification. MALDI MSI in combination with linear ion trap MS was required to study the distribution of the complex polymers cellulose and hemicelluloses in poplar tissue (Lunsford et al., 
Table 1 | Published literature describing the application of MS imaging for the analysis of small molecules from plant material.

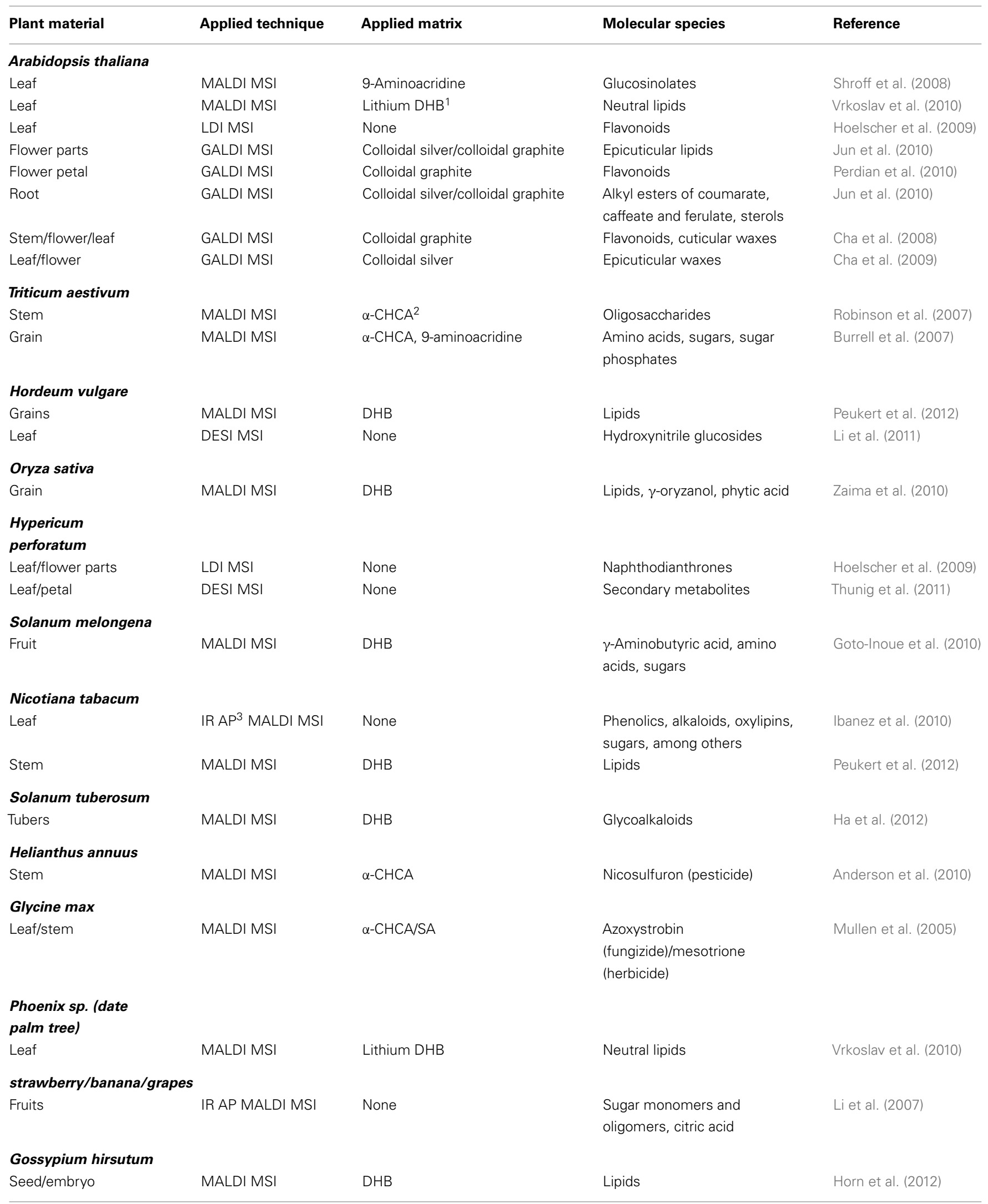


Table 1 | Continued

\begin{tabular}{|c|c|c|c|c|}
\hline Plant material & Applied technique & Applied matrix & Molecular species & Reference \\
\hline \multicolumn{5}{|l|}{ Populus sp. } \\
\hline Stem & MALDI MSI & $\mathrm{DHB}$ & $\begin{array}{l}\text { Oligosaccharides, } \\
\text { polysaccharides }\end{array}$ & Lunsford et al. (2011) \\
\hline \multicolumn{5}{|l|}{ Vaccinium } \\
\hline \multicolumn{5}{|c|}{ ashei(blueberry) } \\
\hline Fruit & MALDI MSI & $\mathrm{DHB}$ & Anthocyanins & Yoshimura et al. (2012) \\
\hline \multicolumn{5}{|c|}{ Malus sp. (Golden } \\
\hline \multicolumn{5}{|c|}{ delicious) } \\
\hline Fruit & MALDI MSI & $\alpha-\mathrm{CHCA}$ & Flavonoids, dihydrochalcones & Franceschi et al. (2012) \\
\hline \multicolumn{5}{|l|}{ Myristica } \\
\hline \multicolumn{5}{|l|}{ malabrica(Lam) } \\
\hline Fruit & DESI MSI & None & Alkaloids & Ifa et al. (2011) \\
\hline \multicolumn{5}{|c|}{ Stevia rebaudiana } \\
\hline Leaf & DESI MSI & None & Diterpenes & Gray et al. (2009) \\
\hline
\end{tabular}

2011). MS spectra alone provided an even distribution of cellulose and hemicelluloses ions; however, when plotting characteristic fragment ions obtained by MS/MS, quite contrasting images were obtained. The authors concluded that tandem MS is necessary to separate isobaric species in order to accurately annotate wood tissue MS images. They also observed reduced background in the MS/MS experiments, which improved the signal-to-background ratio in the image analysis (Lunsford et al., 2011).

\section{MSI ANALYSIS OF PEPTIDE AND PROTEIN PATTERNS}

Mass spectrometry-based imaging of proteins is of particular interest for biomedical research. However, the mass range for sensitive detection of proteins in tissue sections is limited. Identification of proteins in imaging experiments is still a challenging task. On tissue digestion using proteolytic enzymes is possible; conversely this procedure increases the complexity of the MS spectra considerably. This fact necessitates high accurate mass measurements (Schober et al., 2011). Another challenge is to keep spatial resolution during tryptic digestion of the proteins on the tissue surface. A protocol has been developed which allowed to achieve a spatial resolution of $50 \mu \mathrm{m}$ (Schober et al., 2012).

So far, few reports describe the MSI analysis of peptides from plant tissues. In situ MALDI MS analysis determined the structure of a modified 12-amino acid peptide (MCLV3), which was derived from a conserved motif in the CLV3 sequence in Arabidopsis callus (Kondo et al., 2006). The spatial distribution of cyclotide peptides was analyzed by MALDI MSI in Petunia leaves (Poth et al., 2012). Cyclotides represent a family of plant peptides and are characterized by a structural feature called the cycline cystine knot. Several reports suggest a role of cyclotides in plant defense. The non-uniform distribution of cyclotides in Petunia leaves would be consistent with such a role (Poth et al., 2012).
Additionally, discriminative peptides in barley grain sections were highlighted as examples in a recent review (Kaspar et al., 2011).

Most protein MSI studies to date are from the field of medicine (Caprioli et al., 1997; Yanagisawa et al., 2003; Schwartz et al., 2005; Goodwin et al., 2008). Spatial distribution of proteins can be used as markers for diagnosis of diseases and to better differentiate between diseased and healthy tissues. Unknown proteins can serve as valuable markers and assist diagnosis and disease treatment. Their identification will be necessary to build a biochemical network representing the molecular events underlying the development of the disease (Mascini and Heeren, 2012). Targeted MSI for proteins was recently performed by means of the combination of immunohistochemistry with MALDI MSI using single chain fragment variable recombinant antibodies (Thiery et al., 2012).

The first report on protein MSI for plants described the detection and identification of the allergenic lipid transfer protein Pru p3 in the peel of the peach fruit by means of electrospray MS identification and MALDI MSI (Cavatorta et al., 2009). Method development for MALDI MSI of proteins was recently published, encouraging the wider application of protein MSI in plant tissues (Grassl et al., 2011). Main constraints for MSI of intact proteins present the rather low protein abundance, the high water content, and the rigid cell walls and abundant air spaces in many plant tissues, resulting mainly in challenging sample preparation. As for the presented soybean sample, the authors propose to prepare and freeze the sample using dry ice immediately after collection to preserve morphology and minimize protein degradation through proteolysis and to avoid breakage and cracking as observed during shock freezing by liquid nitrogen. Optimal section thickness for soybean seedlings has been found to be 10 - to $15-\mu \mathrm{m}$ from frozen sections. However embedding in gelatin showed an improvement in localization, lateral resolution, and reproducibility, with some 
Table 2 | Schematic representation of the current status of MSI in plant science.

\begin{tabular}{|c|c|c|c|c|}
\hline Plant Material & Sample Preparation & MSI Approach & Image Analysis & Identification Strategies \\
\hline \multirow{2}{*}{$\begin{array}{l}\text { - Leaf } \\
\text { - } \text { Stem } \\
\text { - } \text { Root } \\
\text { - Flower } \\
\text { - Pruit } \\
\text { (hairs, of organs } \\
\text { - Single cells }\end{array}$} & - $\frac{\text { Tissue analysis: }}{\text { Sectioning }}$ & $\begin{array}{l}\text { - } \quad \text { MALDI MSI } \\
\text { - LDI MSI }\end{array}$ & \multirow[b]{2}{*}{$\begin{array}{l}\text { - Data preprocessing } \\
\text { - Multivariate analysis }\end{array}$} & $\begin{array}{l}\text { Direct approaches: } \\
\text { MALDI MSI + linear ion trap MS } \\
\text { (only shown for small molecules) }\end{array}$ \\
\hline & $\begin{array}{l}\frac{\text { Direct and indirect }}{\text { surface analysis: }} \\
\text { Tissue imprinting } \\
\text { - Tissue mounting }\end{array}$ & $\begin{array}{ll}\text { - } & \text { DESI MSI } \\
\text { - } & \text { IR AP MALDI MSI } \\
\text { - } & \text { GALDI MSI } \\
\text { - } & \text { IR AP MSI MALDI MSI }\end{array}$ & & $\begin{array}{l}\text { Indirect approaches: } \\
\text { On tissue digestion + MS/MS of } \\
\text { peptides } \\
\text { Laser microdissection +targeted } \\
\text { analyses (e.g. LC-MS, GC-MS) }\end{array}$ \\
\hline
\end{tabular}

For molecular species targeted by the different approaches please refer also to Table $\mathbf{1}$.

loss in signal-to-noise. Soaking tissues in sucrose, and thus filling of air spaces between cells, dramatically improves cryosectioning and the lateral resolution during imaging. A wash with ice-cold 2propanol enabled the fixation of proteins, and removed lipids and salts substantially. Complete drying of the tissue sections was also shown to be important in order to preserve protein localization. Best reproducibility in ion intensity as well as spatial resolution was observed when using sinapinic acid (SA) as a matrix. Matrix application was performed by means of vibrational spray (Image Prep, Bruker Daltonics, Germany) with an optimized protocol for spraying and drying cycles. For MALDI MSI measurement the authors suggested to adjust a resolution of $30-100 \mu \mathrm{m}$ for the laser raster points. In addition, the authors comprehensively reviewed approaches enabling the identification of MSI protein targets either "on tissue" or by extraction procedures aiming to conserve the spatial localization (Poth et al., 2012). However, none of these identification approaches has been successfully applied to plants so far.

\section{EVALUATION OF MSI DATA SETS}

Analysis of multiple tissue sections at high spatial resolution necessarily generates large data sets providing challenges for the subsequent data mining. A number of imaging software packages are available, both open source (e.g., BioMap, see http://www.maldimsi.org/) as well as commercial solutions (Kaspar et al., 2011). Still the visualization as well as the statistical treatment of large data sets requests further developments. Identification of unknown compounds requires high resolution mass spectrometry. Frequently, additional efforts are necessary to annotate compounds of interest, such as targeted analysis of micro-dissected materials or other complementary approaches. Software capable of handling three-dimensional datasets will be another essential tool for visualization.

\section{REFERENCES}

Anderson, D. M. G., Carolan, V. A., Crosland, S., Sharples, K. R., and Clench, M. R. (2010). Examination of the translocation of sulfonylurea herbicides in sunflower plants by matrix-assisted laser desorption/ionisation mass spectrometry imaging. Rapid Commun. Mass Spectrom. 24, 3309-3319.

Burrell, M. M., Earnshaw, C. J., and Clench, M. R. (2007). Imaging

\section{FURTHER DEVELOPMENT OF MS IMAGING}

Spatial resolution of current instrumentation for LDI/MALDI MSI is restricted to $10-20 \mu \mathrm{m}$. MSI at cellular and in particular sub-cellular resolutions requires improvements in the techniques. Recently, the Caprioli group has developed transmission geometry MALDI MS allowing submicron spatial resolution (Zavalin et al., 2012). As a feature, the transmission geometry vacuum ion source enabled to irradiate the back of the sample with the laser beam. The development of this laser optics together with an adjusted sample preparation protocol allowed sufficient sensitivity of the instrument also at submicron spatial resolution (Zavalin et al., 2012). Further implementation of MSI will benefit from such specific developments, but also from the overall advances still seen in bio-analytical mass spectrometry instrumentation.

\section{CONCLUSION}

Mass spectrometry imaging has recently been introduced into plant sciences mostly focused on the spatial distribution of low molecular weight compounds, including primary and secondary plant metabolites as well as cyclic peptides (Table 2). These studies will encourage extension of the approach toward other plants systems and applications. Sample preparation, selection of matrix substances and application of the matrix are critical to obtain images of sufficient quality using MALDI MSI. DESI MSI together with a number of other aforementioned imaging approaches provides strategies with complementary applications. Most promising are future developments in tandem MS technologies, such as combining MALDI MSI with high resolution MS for identification, and thus enabling the correlation of molecular distribution pattern to particular molecular networks and tissue function, and the quantitation of differential distributions. The studies already published will guide the further implementation of tandem MSI techniques for plant samples and extend the range of possible applications.

matrix assisted laser desorption ionization mass spectrometry: a technique to map plant metabolites within tissues at high spatial resolution. J. Exp. Bot. 58,757-763.
Caprioli, R. M., Farmer, T. B., and Gile, J. (1997). Molecular imaging of biological samples: localization of peptides and proteins using MALDI-TOF MS. Anal. Chem. 69, 4751-4760. 
Cavatorta, V., Sforza, S., Mastrobuoni, G., Pieraccini, G., Francese, S., Moneti, G., et al. (2009). Unambiguous characterization and tissue localization of Pru P 3 peach allergen by electrospray mass spectrometry and MALDI imaging. J. Mass Spectrom. 44, 891-897.

Cha, S. W., Song, Z. H., Nikolau, B. J., and Yeung, E. S. (2009). Direct profiling and imaging of epicuticular waxes on Arabidopsis thaliana by laser desorption/ionization mass spectrometry using silver colloid as a matrix. Anal. Chem. 81, 2991-3000.

Cha, S. W., Zhang, H., Ilarslan, H. I., Wurtele, E. S., Brachova, L., Nikolau, B. J., et al. (2008). Direct profiling and imaging of plant metabolites in intact tissues by using colloidal graphite-assisted laser desorption ionization mass spectrometry. Plant J. 55, 348-360.

Chaurand, P. (2012). Imaging mass spectrometry of thin tissue sections: a decade of collective efforts. J. Proteomics 75, 4883-4892.

Chughtai, K., and Heeren, R. M. A. (2010). Mass spectrometric imaging for biomedical tissue analysis. Chem. Rev. 110, 3237-3277.

Franceschi, P., Dong, Y. H., Strupat, K., Vrhovsek, U., and Mattivi, F. (2012). Combining intensity correlation analysis and MALDI imaging to study the distribution of flavonols and dihydrochalcones in Golden Delicious apples. J. Exp. Bot. 63, 1123-1133.

Goodwin, R. J. A., Pennington, S. R., and Pitt, A. R. (2008). Protein and peptides in pictures: imaging with MALDI mass spectrometry. Proteomics 8, 3785-3800.

Goto-Inoue, N., Setou, M., and Zaima, N. (2010). Visualization of spatial distribution of gammaaminobutyric acid in eggplant (Solanum melongena) by matrixassisted laser desorption/ionization imaging mass spectrometry. Anal. Sci. 26, 821-825.

Grassl, J., Taylor, N. L., and Millar, A. H. (2011). Matrix-assisted laser desorption/ionisation mass spectrometry imaging and its development for plant protein imaging. Plant Methods $7,21$.

Gray, J., Bevan, M., Brutnell, T., Buell, C. R., Cone, K., Hake, S., et al. (2009). A recommendation for naming transcription factor proteins in the grasses. Plant Physiol. 149, 4-6.

Greer, T., Sturm, R., and Li, L. J. (2011). Mass spectrometry imaging for drugs and metabolites. J. Proteomics 74, 2617-2631.
Ha, M., Kwak, J. H., Kim, Y., and Zee, O. P. (2012). Direct analysis for the distribution of toxic glycoalkaloids in potato tuber tissue using matrixassisted laser desorption/ionization mass spectrometric imaging. Food Chem. 133, 1155-1162.

Hoelscher, D., Shroff, R., Knop, K., Gottschaldt, M., Crecelius, A., Schneider, B., et al. (2009). Matrixfree UV-laser desorption/ionization (LDI) mass spectrometric imaging at the single-cell level: distribution of secondary metabolites of Arabidopsis thaliana and Hypericum species. Plant J. 60, 907-918.

Horn, P. J., Korte, A. R., Neogi, P. B., Love, E., Fuchs, J., Strupat, K., et al. (2012). Spatial mapping of lipids at cellular resolution in embryos of cotton. Plant Cell 24, 622-636.

Horn, P. J., Ledbetter, N. R., James, C. N., Hoffman, W. D., Case, C. R., Verbeck, G. F., et al. (2011). Visualization of lipid droplet composition by direct organelle mass spectrometry. J. Biol. Chem. 286, 3298-3306.

Ibanez, A. J., Scharte, J., Bones, P., Pirkl, A., Meldau, S., Baldwin, I. T., et al. (2010). Rapid metabolic profiling of Nicotiana tabacum defence responses against Phytophthora nicotianae using direct infrared laser desorption ionization mass spectrometry and principal component analysis. Plant Methods 6, 14.

Ifa, D. R., Srimany, A., Eberlin, L. S., Naik, H. R., Bhat, V., Cooks, R. G., et al. (2011). Tissue imprint imaging by desorption electrospray ionization mass spectrometry. Anal. Methods 3, 1910-1912.

Jun, J. H., Song, Z. H., Liu, Z. J., Nikolau, B. J., Yeung, E. S., and Lee, Y. J. (2010). High-spatial and highmass resolution imaging of surface metabolites of Arabidopsis thaliana by laser desorption-ionization mass spectrometry using colloidal silver. Anal. Chem. 82, 3255-3265.

Kaspar, S., Peukert, M., Svatos, A., Matros, A., and Mock, H. P. (2011). MALDI-imaging mass spectrometry - an emerging technique in plant biology. Proteomics 11, 1840-1850.

Kondo, T., Sawa, S., Kinoshita, A., Mizuno, S., Kakimoto, T., Fukuda, H., et al. (2006). A plant peptide encoded by CLV3 identified by in situ MALDI-TOF MS analysis. Science 313, 845-848.

Lee, Y. J., Perdian, D. C., Song, Z. H., Yeung, E. S., and Nikolau, B. J. (2012). Use of mass spectrometry for imaging metabolites in plants. Plant J. 70, 81-95.

Li, B., Bjarnholt, N., Hansen, S. H., and Janfelt, C. (2011). Characterization of barley leaf tissue using direct and indirect desorption electrospray ionization imaging mass spectrometry. J. Mass Spectrom. 46, 1241-1246.

Li, Y., Shrestha, B., and Vertes, A. (2007). Atmospheric pressure molecular imaging by infrared MALDI mass spectrometry. Anal. Chem. 79, 523-532.

Lunsford, K. A., Peter, G. F., and Yost, R. A. (2011). Direct matrixassisted laser desorption/ionization mass spectrometric imaging of cellulose and hemicellulose in populus tissue. Anal. Chem. 83, 6722-6730.

Mascini, N. E., and Heeren, R. M. A. (2012). Protein identification in mass-spectrometry imaging. Trends Analyt. Chem. 40, 28-37.

Mullen, A. K., Clench, M. R., Crosland, S., and Sharples, K. R. (2005). Determination of agrochemical compounds in soya plants by imaging matrix-assisted laser desorption/ionisation mass spectrometry. Rapid Commun. Mass Spectrom. 19, 2507-2516.

Muller, T., Oradu, S., Ifa, D. R., Cooks, R. G., and Krautler, B. (2011). Direct plant tissue analysis and imprint imaging by desorption electrospray ionization mass spectrometry. Anal. Chem. 83, 5754-5761.

Nemes, P., and Vertes, A. (2012). Ambient mass spectrometry for in vivo local analysis and in situ molecular tissue imaging. Trends Analyt. Chem. 34, 22-34.

Perdian, D. C., Schieffer, G. M., and Houk, R. S. (2010). Atmospheric pressure laser desorption/ionization of plant metabolites and plant tissue using colloidal graphite. Rapid Commun. Mass Spectrom. 24, 397-402.

Peukert, M., Matros, A., Lattanzio, G., Kaspar, S., Abadía, J., and Mock, H.-P. (2012). Spatially resolved analysis of small molecules by matrix-assisted laser desorption/ionization mass spectrometric imaging (MALDI-MSI). New Phytol. 193, 806-815.

Poth, A. G., Mylne, J. S., Grassl, J., Lyons, R. E., Millar, A. H., Colgrave, M. L., et al. (2012). Cyclotides associate with leaf vasculature and are the products of a novel precursor in Petunia (Solanaceae). J. Biol. Chem. 287, 27033-27046.

Rauser, S., Marquardt, C., Balluff, B., Deininger, S. O., Albers, C., Belau, E., et al. (2010). Classification of HER2 receptor status in breast cancer tissues by MALDI imaging mass spectrometry. J. Proteome Res. 9, 1854-1863.
Robinson, S., Warburton, K., Seymour, M., Clench, M., and Thomas-Oates, J. (2007). Localization of watersoluble carbohydrates in wheat stems using imaging matrix-assisted laser desorption ionization mass spectrometry. New Phytol. 173, 438-444.

Schober, Y., Guenther, S., Spengler, B., and Rompp, A. (2012). Highresolution matrix-assisted laser desorption/ionization imaging of tryptic peptides from tissue. Rapid Commun. Mass Spectrom. 26, 1141-1146.

Schober, Y., Schramm, T., Spengler, B., and Rompp, A. (2011). Protein identification by accurate mass matrix-assisted laser desorption/ionization imaging of tryptic peptides. Rapid Commun. Mass Spectrom. 25, 2475-2483.

Schwamborn, K., Krieg, R. C., Jirak, P., Ott, G., Knuchel, R., Rosenwald, A., et al. (2010). Application of MALDI imaging for the diagnosis of classical Hodgkin lymphoma. J. Cancer Res. Clin. Oncol. 136, 1651-1655.

Schwartz, S. A., Weil, R. J., Thompson, R. C., Shyr, Y., Moore, J. H. Toms, S. A., et al. (2005). Proteomicbased prognosis of brain tumor patients using direct-tissue matrixassisted laser desorption ionization mass spectrometry. Cancer Res. 65 , 7674-7681.

Shroff, R., Vergara, F., Muck, A., Svatos, A., and Gershenzon, J. (2008). Nonuniform distribution of glucosinolates in Arabidopsis thaliana leaves has important consequences for plant defense. Proc. Natl. Acad. Sci. U.S.A. 105, 6196-6201.

Svatos, A. (2010). Mass spectrometric imaging of small molecules. Trends Biotechnol. 28, 425-434.

Takáts, Z., Wiseman, J. M., Gologan, B., and Cooks, R. G. (2004). Mass spectrometry sampling under ambient conditions with desorption electrospray ionization. Science 306, 471-473.

Thiery, G., Mernaugh, R. L., Yan, H. P., Spraggins, J. M., Yang, J. H., Parl, F. F., et al. (2012). Targeted multiplex imaging mass spectrometry with single chain fragment variable (SCFV) recombinant antibodies. J. Am. Soc. Mass Spectrom. 23, 1689-1696.

Thunig, J., Hansen, S. H., and Janfelt, C. (2011). Analysis of secondary plant metabolites by indirect desorption electrospray ionization imaging mass spectrometry. Anal. Chem. 83, 3256-3259. 
Vickerman, J. C. (2011). Molecular imaging and depth profiling by mass spectrometry-SIMS, MALDI or DESI? Analyst 136, 2199-2217.

Vrkoslav, V., Muck, A., Cvacka, J., and Svatos, A. (2010). MALDI imaging of neutral cuticular lipids in insects and plants. J. Am. Soc. Mass Spectrom. 21, 220-231.

Yanagisawa, K., Shyr, Y., Xu, B. G. J., Massion, P. P., Larsen, P. H., White, B. C., et al. (2003). Proteomic patterns of tumour subsets in non-small-cell lung cancer. Lancet 362, 433-439.

Yoshimura, Y., Enomoto, H., Moriyama,

T., Kawamura, Y., Setou, M., and
Zaima, N. (2012). Visualization of anthocyanin species in rabbiteye blueberry Vaccinium ashei by matrix-assisted laser desorption/ionization imaging mass spectrometry. Anal. Bioanal. Chem. 403, 1885-1895.

Zaima, N., Goto-Inoue, N., Hayasaka, T., and Setou, M. (2010). Application of imaging mass spectrometry for the analysis of Oryza sativa rice. Rapid Commun. Mass Spectrom. 24, 2723-2729.

Zavalin, A., Todd, E. M., Rawhouser, P. D., Yang, J. H., Norris, J. L., and Caprioli, R. M. (2012). Direct imaging of single cells and tissue at sub-cellular spatial resolution using transmission geometry MALDI MS. J. Mass Spectrom. 47, 1473-1481.

Conflict of Interest Statement: The authors declare that the research was conducted in the absence of any commercial or financial relationships that could be construed as a potential conflict of interest.

Received: 11 January 2013; paper pending published: 08 February 2013; accepted: 22 March 2013; published online: 19 April 2013.
Citation: Matros A and Mock H-P (2013) Mass spectrometry based imaging techniques for spatially resolved analysis of molecules. Front. Plant Sci. 4:89. doi 10.3389/fpls.2013.00089

This article was submitted to Frontiers in Plant Proteomics, a specialty of Frontiers in Plant Science.

Copyright (c) 2013 Matros and Mock. This is an open-access article distributed under the terms of the Creative Commons Attribution License, which permits use, distribution and reproduction in other forums, provided the original authors and source are credited and subject to any copyright notices concerning any third-party graphics etc. 